\title{
A Journey in Gender
}

\section{Aiyyana Maracle}

Aiyyana, an award-winning multi-disciplinary artist whose work has been shown internationally, is based in Vancouver. Her current major projects include a half-hour television documentary on her work; an autobiography, Chronicle of a Transformed Woman; and an operatic performance, with the assistance of the Banff Centre for the Arts. Alongside her artistic practice, Aiyyana (marawood@telus.net) engages herself as a speaker on issues of gender, culture, and race.

I am pleased to have the opportunity to present a perception of gender that has existed, and continues to exist, quite apart from the prevailing Euro-North American norm epitomized by an inflexible, Christian, pseudoscientific declaration of one's being as either male or female. This immutable declaration of Western society is based on no evidence or criterion other than a single answer to the question "What are its genitalia?"

While I present this as a scholarly paper, you may notice that I hold no degrees, there are no extra letters following my name. My only 'papers proving I know something' are a few awards I have received for my work as an artist. Not to have sought a degree has been my conscious decision. Furthermore, you may notice that this paper does not necessarily conform to the accepted protocols of academic writing. This is also by choice. Native thought and logic follow another path, and I fear too much is lost in the attempt at translation. My primary qualifications are quite simply that I am a Mohawk, a Grandmother, a multidisciplinary artist, and a transformed woman who loves women. I see myself as a transformed woman who loves women, and not as a transexual, lesbian, or dyke. Though I may fit the definition of the European concept of transsexuality, as far as I am concerned, my being and transformation are based in the historical cultural continuum of North America's Indigenous people. 
I feel my choice of "transformed woman" to be a more appropriate term in that it follows the logic and structure of Indigenous languages, where things are named more by functionality or by interrelation. Also, in keeping with my cultural perspective, I make no attempt scientifically to 'prove' anything; my being and life and those of others are the evidence for my assertions in this paper. In our societies, scientific proof was derived over time in that something worked, or it did not. This plant, or these combinations of plants and/or minerals will heal this or that. We did not need to break down some herb into minute parts to 'discover' how or why it worked. We knew that it did, used it, and were grateful. We knew which particular ceremonies or prayers could influence the healing process. And we knew what kinds of social structures would lead to healthy communities. All of this was based on the premise that we are merely a part of this world, and must find our way to live in a healthy balance with those around us, in accordance with directives received from our goddesses and gods. The Grandmothers had surrounded us with all that was necessary to lead a healthy life. And we as human beings, 'the people', were charged with its perpetual maintenance. Most Native people continue to see ourselves as caretakers of our world, and not its master. If you must have more than what I offer to satisfy your requirements of proof, I may point you in the direction, but you will need to find it yourself.

This paper's alternative perception of gender cannot be properly understood outside the context of Native social structures and sense of spirituality. When Europeans (and I include North Americans in this) view Native cultures, it must be remembered that it is not the same as when Europeans view the differences in their own respective cultures, with their common Christian history and essential worldview. The worldviews of Europeans and Indigenous peoples are indeed worlds apart: how we see our position in relation to everything else that makes up our world; how we view spirit and spirituality; how these primary perceptions translate into societal structures and practices. A majority of North America's original inhabitants were matrilineal, where familial lineage was traced through the women. Marriage, and its formalization and dissolution, was drastically different from its European counterpart. Household structure and organization in Native societies in the main were built around a clan system, and not around a nuclear family of a father, mother, and two 


\section{8 / Maracle}

children. A wonderful elaboration of the foregoing can be found in Paula Gunn Allen's The Sacred Hoop. In the chapter "Hwame, Koshkalaka, and the Rest" (245-61), she lays out a matrilineal social structure with its interrelationships in order to establish that there were bondings between some women (that were akin to lesbianism), as well as unions between women and men, and men and other men. While her intent was to establish that, historically, Native people have acknowledged that there was sexuality beyond heterosexuality, I would respectfully go further to say that Allen refers to gender as much, if perhaps not more, than sexuality.

The primary source and voice in this paper is myself, although I do occasionally quote from or refer to other writers' works. ${ }^{1}$ I have difficulty with the notion of 'objectivity' that colors so much of the social scientific research on Indigenous people, particularly in earlier work (before 1950). These earlier works' notion of 'objectivity,' to varying degrees, has continued to influence both recent and present work regarding Native people. This 'objective' point of view not only supposedly removes and distances one's self from the object of study to a place of dispassionate observation, but also removes the passion or energy - the spirit - from the subject being observed. While I readily recognize that in 'accepted scientific research' one does not normally use one's self as the subject of a study, this journey in gender is quite outside of normalcy. As well, for anyone outside of this reality to hope to understand what the experience is, its raison d'être, I believe that the words and information must come from those of us brought to being through this phenomenon. As Mao is famous for saying, "To know a pear, is to eat the pear." As for the existing literature regarding Indigenous people generally: since much has been written about us and, until recently, very little by us, I am not only compelled to add my voice, but am also honored to inject another sensibility into the discussion of gender. The inclusion of Indigenous peoples'

\footnotetext{
'At this point, I would like to acknowledge the body of work around issues of gender created by lesbian/feminist scholars over the past three decades. However, as much of it is written from a European perspective, I found nothing particularly useful toward this discussion, even within the literature by women of color, including: Makeda Silvera's Piece of my Heart; Gloria Anzuldúa's Making Face, Making Soul; Carole S. Vance's Pleasure and Danger; Ann Snitow, Christine Stansell and Sharon Thompson's Powers of Desire; Valentine Moghadam's Identity Politics and Women; and E. D. Nelson and B. W. Robinson's Gender in the 1990s.
} 
writings into the canons of North America has been a most necessary step in the need for non-Native peoples to understand who Indigenous people truly are, as part of our mutual quest to come to an equitable settlement of a grievous history, and to find a more humane way to coexist on this land. In this same vein, I offer this contribution to an emerging public discourse on issues of gender identity outside of or beyond the male/female dichotomy.

What I wish to posit here is, for most readers, an alternative way of perceiving and understanding gender beyond the current polarized notion of male/female. I refer to this as an Indigenous sense of gender: a perception of gender that would seem to be considerably more humane and holistic, perhaps, than the antiquated, moralistic conception dominant within Western society. This gender I refer to remains largely intact as a global Indigenous sensibility, spanning many cultures, with varying manifestations, but greater commonalities. This perspective is really but another social construct whose foundation is very much based in Native peoples' sense of spirit, with concordant social positions created to acknowledge and honor those who were female/male, yet were neither, nor both, but outside of, or beyond.

For a very long time prior to the colonial and postcolonial periods (this little blip on the trajectory of our history), Indigenous peoples brought into being and practiced a social organization that viewed gender in the same continuum, with the same sense of circularity and integral interrelations which we attached to everything else in life. For virtually all societies, whether European-based or Indigenous, the female/male, heterosexual model has been predominant, mostly for the rather obvious reason of procreation. However, there is also a reality among all humanity, that for various, quite intimate reasons, sometimes an individual does not strictly adhere to this thing called man or woman; they feel neither completely, yet are made of both, and maybe something more. How different races and societies through time have approached this human reality has fundamentally shaped our worlds individually and collectively.

One's determination of gender is among the first few cognitions an individual makes. Without negating existing research and writing on this subject, for the purposes of this paper I would like to offer my simplified version. We are born; we begin to gain awarenesses of our world and the people in it. These are not so much moments of 
conscious awareness as they are perhaps innate understandings, semior unconsciously brought to light through interaction with our world. I need to breathe. I need to eat. If I cry, someone will feed me. If I cry like this, someone will clean me. I am a person, a human being. Kind of like these people around me who care for me. Different from these furry, fuzzy, four-legged creatures. Different from those other little creatures that sing so prettily, then fly away. And somewhere early on in here in the first few years, this awareness of gender clicks in, bit by bit. There seem to be two different kinds of people: one who mostly cares for me, talks and coos softly to me, feeds me from her breast, while the other one (who is not always there) does not seem able to feed me, but is bigger, even the voice, which is also somewhat lower. Amid all this, the question dawns, and the search for affinity begins. Where do I fit in? Do I belong to this world of women, or of men? Minus the intrusion of dictates from outside, the answer to that question does not come from the child's understanding of anatomy, but from its spirit. I am a girl-child. I am a boy. And usually that is as far as it goes. Problem solved. But once in a while, this boy-girl thing does not fit somehow, the body and spirit are out of sync. And here is the crux of this cultural rift between us. How does society respond? What choices does society offer this special child?

For the great majority of North America's original inhabitants (Lakota, Hopi, Navajo, Cree, Anishnabe, Haudenosaune, Shoshone, Sac and Fox, Timucua, Zuni, Crow, Paiute, Tolowa, Heiltsuk, Salish, Kwakuitul, to name a few), the answer to the determination of gender comes in large part through our sense of spirit. We maintain the belief that those among us who are different are the way they are as a result of a special gift from The Grandmothers. It matters not whether that difference is from birth or brought about through a revelation, or in a vision. For most Native people, choice is a sacred thing. There is the freedom, the right to choose, in all matters relating to our being. So that things remain in balance, there are also social responsibilities attached to these 'human rights'. Gender, as the keystone in the foundation of everything else that we are, must of course be the determination of the individual - it can be made only by that child. Truly, no other can know until that individual publicly expresses an affinity for whichever gender they know themselves to be. In many instances this determination of gender occurs during early childhood. However, in keeping with our sense of spirit(uality), if later in life 
one experiences a vision, a message from The Grandmothers, then a person is free to adopt another gender role at whatever point they deem appropriate during adulthood.

Among Indigenous people, in their acknowledgment of these other genders, various social positions were created for these people who are neither woman nor man. These special people were recognized as having all the knowledge of these genders and more, so by and large the roles of these special people were ones where mediation between man and woman and spirit was required. In ceremony, physically and metaphorically, our place was between the women and men. We were healers, people of medicine, we were storytellers, seers and visionaries, artists and artisans - we were among the keepers of the culture. Our counsel was often sought. To quote John Lame Deer, from his book Lame Deer, Seeker of Visions:

Winkte are people who dress like women, look like women, and act like women. They do so by their own choice or in obedience to a dream. They are not like others, but are Wakan, the Great Spirit made them Winktes and we accept them as such. To us, a person is what nature, or their dreams, makes them. In our tribe we go to a Winkte to give a newborn child a secret name. They have the gift of prophecy, and the secret name a Winkte gives to a child is believed to be especially powerful and effective. [Black Elk, Sitting Bull, Crazy Horse, all had these secret names.] ... Tribal councils would decide almost nothing without consulting Winktes. (97)

These special people occupied revered positions among the people. We did not so much hold power in the community, as we had influence. By this I mean that while we held no decisive authority in the community, our counsel was often sought, both by individuals and by the collective, before decisions were made. Gifted by The Grandmothers with a 'sight' beyond that of most, people wished to know how we saw the world so they could plan their own course.

In North America, it was well into the twentieth century before this situation changed substantially. Not to deny the rapacious violence and self-righteous racial superiority which characterized and underlaid the colonization of the Americas, but this thing that had so enraged the initial conquistadors, missionaries, alleged explorers, and settlers, this thing that really was at the root of their declaration of us as immoral, was our perception of gender. In the European mind, 
dressing in a half-naked manner made Native people uncivilized; our practice of gender, and the sexualities derived from these genders, made us immoral. And yet this understanding of gender has survived reasonably intact in spite of the devastations of a few centuries of colonialism on our cultures, land, and being. In many Native communities, these special people have been subjected to hiding and homophobia for only two or three generations. For a few, such as the Rotinonhsyonni (Six Nations), the repression has taken place over seven generations. Quite a few peoples (those more geographically removed) have survived with less damage. The length of colonial contact and/or the length of the imposition of the church, as well as proximity to major settler populations, have been the determinants of the moment when the genders beyond male and female went underground. My own research over the last eleven years, my discussions with my gender peers and with the elders among the Indigenous peoples of the Americas, of the South Pacific Islands (particularly Australia and New Zealand), and of parts of South East Asia tells me that this pattern holds relatively true for a vast majority of Indigenous people. (In my research, I made no attempt to gather statistics. Initially, my interest was purely personal and extended only to verifying my speculation that most Indigenous peoples held concepts of genders beyond male and female.)

In 1990, the Maori Writers and the New Zealand National Library hosted a delegation of seven Canadian Native writers and publishers that included myself. They showed us around the North Island for five weeks, on and off their mareis ${ }^{2}$ in both urban and rural settings. The tour was planned around spending the middle week at the Queen's marei and attending the Third International Conference on Indigenous Education. Throughout our time in New Zealand, it was refreshing to experience the natural acknowledgment of the varied sexualities I observed among our hosts and the many other Maoris we met in various social contexts. The question of men-loving-men or womenloving-women did not exist. And for the first time, I heard references to a couple of trans women, spoken of with respect and something more than affection. The social/sexual pairings or inclinations of these different people seemed to be regarded with no more interest than

\footnotetext{
${ }^{2} \mathrm{~A}$ marei is not quite like a reservation as we know it; it is more like the cultural center for the community.
} 
whether someone wears their hair long or short, is thin or hefty, is tall or not. Over the next few years, at various venues across North America, I would occasionally see a couple of Maori elders who I had previously met at two of the Indigenous Education Conferences. Along with their elder status in the Maori hierarchy, they held a number of degrees, had many years of teaching experience, and even more of dealing with the cultural bureaucracy of the New Zealand government. Having met them initially while I was still living as a man, they accepted my change of gender with no great surprise. For them, I was woman, but not, yet more, and they treated me so, with respectful deference, making no comment on the change until I broached the subject. From their own cultural understanding they recognized and acknowledged me, telling me that the Maori also had people like myself. I explained my understanding of what I termed as "this Indigenous sense of gender" (much as it is laid out in this paper), and they concurred. On a forthcoming trip to New Zealand and Australia, again as an artist/cultural worker, only now also as a trans woman, I look forward to being able to further my understanding of these other, different genders.

On the flip side is my experience among my own Kanyen'kehaka (Mohawk) people. I will cite one representative experience. A few years ago, while I was a rising star in Vancouver's theater scene, I would occasionally be approached by another Mohawk woman also living in Vancouver. This particular woman, who worked within Vancouver's school system, had brought some students to see a play I had directed. Over the three months after our initial meeting we had exchanged a couple of casual phone calls, until one day she called to invite me for breakfast. She had just returned from her summer break, part of which she had spent back home on our reserve. She told me that she had spoken to her dad about me. Her dad is regarded as a very knowledgeable, traditionally oriented man, and is well respected. His response was, "We didn't have people like that." He then told her that, in keeping with 'tradition,' (for him, the Code of Handsome Lake), in following 'the good business,' "We should treat all people well," implying that she should be polite to me, humor me, as it were. Apparently, she was somehow to treat me well, while denying the essence of who I am, to herself as well as to me. And, understandably, she did so, because her father, a knowledgeable traditional man, a follower of Handsome Lake's Code, had said so. Just as 


\section{4 / Maracle}

understandably, and with as much respect, I have great difficulty with his declaration of a polarized, immutable gender system among our people. Having heard this and similar statements from other sources (including my very Christian father, loud in his unspokenness), I could, as my friend the dutiful daughter did, unquestioningly accept this. However, this would mean denying my existence. And I can no longer do that.

To resolve this dilemma for myself, I needed once again to reexamine history as it has been presented. As Six Nations (also known as Iroquois) people, we are among the longest colonized nations in North America. Although many of the eastern nations did not survive the first century of contact with Europeans, the Iroquois survived that initial period relatively intact. This can be directly attributed to the fact that, unlike the other smaller Native nations in eastern North America, geographically and militarily (and thus economically), the Iroquois were of the utmost importance both to the French and to the British in laying the foundations of their colonial endeavors. The French and the British both considered the Iroquois, and Mohawks particularly, to be the most formidable warriors they had encountered in the New World. To further their own colonial ambitions, these two European powers in turn curried favor with the Iroquois, seeking alliances. These alliances contributed to the development and maintenance of favorable relationships with the powers of Europe which lasted throughout the initial colonial process. However, the ensuing period of expanded settlement under the British, the European Seven Years War, the British assault on the French-Canadians at Quebec, and the American Revolution left the Iroquois devastated by military defeats, the loss of lives to war and disease, and the dispossession of land. ${ }^{3}$

We were dispossessed not only of the land of our ancestors, but, perhaps more importantly, also of something less tangible: the sense of who we were, to whom we owed allegiance and loyalty in the political, social, and spiritual realm. Thayendanegea (and most Mohawks, Oneidas, and Tuscaroras) had already adopted Christianity (and its attendant social mores) long before being forced to move north into Canada. The Code of Handsome Lake, which is the basis

${ }^{3}$ For an account of modern Mohawk history, see Brian Maracle, esp. 21-22. 
of the 'traditional religion' of the Mohawk, is itself based on the visions Handsome Lake had as the seventeenth century became the eighteenth, and the Iroquois became who they had to be to survive in the rapidly changing circumstances of those times. Already, through intimate association both with the French and with the English, we were a profoundly changed people from who we had been only a couple of hundred years earlier. Yet few would admit it, then or now. And again, in relative terms, in the colonial scheme, we were treated quite well at first, with a rare acknowledgment of equality. But maybe that was the root of the problem, these profound unseen changes: the acceptance of the invitation to a superior position over other Native peoples in the eyes of the Europeans and their colonial scheme.

A bit of a digression here to the personal: for a good part of my life, I have pondered over the awesome changes my greatgrandmother saw occurring in the world around her. She was over 100 years old when she departed in 1978 , a devout Christian woman, matriarch to a few hundred souls that were her family. She witnessed tremendous change in her world, within her lifetime. Yet my greatgramma's lifetime was just a quarter of the time that Six Nations people have been engaged with colonialism. Change, conscious and not so conscious, voluntary and not so voluntary, occurred at a rate that is hard to imagine. And then there were my parents (veterans of World War II), who were forced to leave the reserve in 1951 when it was determined by the Indian Agent of the day that my father really was not an Indian after all; hence, he could not hold title to land at Six Nations. His name did not appear in the register, so therefore he could not be part of Six Nations. Though my mother's name did appear in the register, since she had chosen to marry this non-Indian, she no longer was part of Six Nations either. "And your kids too!" Simple as that. I did not learn of this, or many other relevant facts about us, until much later. When I was growing up in my parents' house, mostly in urban settings, their determined pursuit of what appeared to be an assimilationist lifestyle, replete with Christianity, made no sense to me. Their even greater determination to instill these values in their children made even less sense to me. I actively resisted. Now, as an adult with hindsight, their choices do make sense (for them in their time). It is not so difficult to see that for my parents, at that time, and under the circumstances of finding themselves dispossessed, it seemed the avenue of survival. 
And here I create my heresy. In my thirties, when I first heard the Code of Handsome Lake recited, I was disturbed. It felt rather Christian. I had felt the same way earlier when I had only heard of Handsome Lake's code, having listened in on some conversations where it was being discussed. There was something in the language: some clever subtleties, some not so clever, other more blatant things. Feeling too young and rather like a traitor, I held my tongue and told myself it was coincidence, perhaps just similarities. After hearing it a few more times, and certainly after seeing and reading the popular translation, that disturbed feeling only intensified, though I did not attempt to articulate it. In order to ground myself culturally for this journey in gender, and to be able to address the declaration that "Mohawks didn't have people like that," I found myself returning to Handsome Lake and his visions. Here I defer to my brother Brian Maracle's words:

The way I see it, it can be compared to the difference between catholics and protestants - one group old and unchanged, the other new and "improved." The Mohawk traditionalists believe only in the religious teachings stemming from the Kayanernen'tsherakowa (the Great Law). The traditionalists who attend the various longhouses (the longhouse people) believe in the Kayaneren'tsherakowa just as much, but they also believe in the Karihwiyo (literally, the Good Business, popularly known as the Code of Handsome Lake).

Skanyatariyo (Handsome Lake) was a Seneca war chief who began preaching a "new and improved" religion among the Mohawk after he had a vision in 1799. In it, he was met by three angelic beings who said that they had been sent by the Creator to ask Handsome Lake to preach against the sins of drinking, witchcraft and abortions. In later visions, Handsome Lake met Jesus Christ and George Washington and toured the Hell-like domain of the Punisher, a place of eternal torture for sinners who refuse to repent and abide by the Karihwiyo.

The longhouse people revere Handsome Lake and have stopped just short of proclaiming him a saint. When they recite the Thanksgiving Address, for example, they offer thanks for all the blessings of Creation, including a special acknowledgment for Skanyatariyo and the Karihwiyo. 
The Mohawk traditionalists, however, thoroughly hate Handsome Lake and his code. They sneer contemptuously at the mention of his name and call the longhouse people "Lakers." They point out that Handsome Lake had his first vision while he was recovering from an extended drinking binge. They complain also that Handsome Lake was influenced by the Quakers and object to the new religious elements he introduced. (149-51)

This story begins to suggest the complexities of arriving at a single conception of Iroquois truth. In trying to retain a semblance of who we had been, while making compromises to accommodate living in this new state, surrounded by the 'civility' of the European settlers in their increasing numbers, it is possible - even likely - that any 'queerness' in gender and/or sexual identities that may have existed among the Iroquois was simply covered up. The Iroquois succumbed to the need to retain their image as a civilized, moral people, to retain a semblance of who they were. For the Christians among the Iroquois, whose beginnings were steeped in and loyal to Victorian mores, denying homosexuality and any gender apart from male and female was part of their doctrine. For the followers of Handsome Lake, denying and condemning 'abnormalities' in sex or gender in their 'new and improved' religion would certainly have made sense at the time. But this does not necessarily mean that "We never had people like that." Am I to believe that, unlike in every other culture and race among humanity, I am the first trans person to have ever appeared among the Mohawk people in their thousands of years? I do not believe this any more than I can believe that it is because "I hang around with all those white folks," and that it somehow rubbed off, or I picked it up like some kind of communicable social disease.

The other alternative for me to consider is that the Iroquois were among the few Native cultures that have always suppressed the notion of fluidity in gender and sexual identities. I find this implausible given the egalitarian nature of Six Nations society and political organization, which was based on consensus, and has long been noted and lauded by many other cultures throughout the world. Consensus did not simply mean getting together, tossing around a few ideas, and coming to agreement in the interest of the common good. It was part of a system that not only encouraged the discussion of differing ideas, but indeed obligated everyone to participate. It was a matter of 
balancing informed choices. So, if you had a vision, or found a new way of doing or looking at things, you were obliged to pursue that line of thought either until it proved fruitless or pointless, or until it was agreed by all the people that this was the course now to follow. It is difficult for me to believe that this egalitarian, matriarchal society which so encouraged the exploration of difference would repress the expression of gender or sexuality beyond the binary of a heterosexual male/female model. ${ }^{4}$

From here on, I will assume that Iroquois, like most of the other Native nations of the Americas, held gender and sexuality as fluid concepts, and that this view has been one of the victims of our colonization. I believe queerness may have existed among the Iroquois. I am uncertain of the existence of any documentation on this human phenomenon among the Mohawks before 1800. I (and a few others) most certainly believe that we who move through genders have always been here among the Iroquois, distributed in much the same way as we are throughout the rest of humanity.

So what genders are there? This requires a bit of a leap. Rather than seeing male and female as the end points on a straight line, try looking at male and female as fixed points sitting opposite one another on a circle. From here, one can imagine an infinite number of points or possibilities between male and female, on this continuum of gender. And I think we would find, along with 'absolute woman' and 'absolute man', man-woman, woman-man, woman-with-man's-heart, manwith-woman's-heart. This much resembles the diversity of the present day. But I would go one step further to suggest that perhaps most of what are presently considered differences in sexuality are not at the same time also differences of gender. A false equation has been

${ }^{4}$ Very recently, I was speaking with an elder Miq Mak woman, a friend and colleague. While telling her about this paper and my position, my outlook on 'the Mohawk question', a puzzled look grew on her face that became tinged with sadness. My friend told me that, during her own travels in the 1960 s, she met a friend from her reserve who was living at Kahnawake. Her friend, a lesbian, was experiencing difficulties with this aspect of herself. She wandered the major urban centers of the eastern seaboard looking to come to terms with her lesbianism. A couple of elder women at Kahnawake recognized this in her and took her in. They told her of a secret society among the Mohawk that was made up of special people like herself, and arranged to have her inducted into this society. My friend does not remember the society's name in Mohawk, but it translated into something like "there are few of us." 
allowed to entrench itself in the popular consciousness: that sex and gender are somehow synonymous. For most people, on some level, there is a recognition that this equation is not accurate. But when it comes down to it, there is a tendency - even among some learned folk - to treat sex and gender as though they were the same. Sex is a visual, biological term, as conveyed in the questions, "What are its genitalia?" and "Which sex organs were you born with?" These are simply physical paraphernalia. The sex act can be physical, mental, and/or spiritual. But by no means does sex determine gender: "Who am I as a person?" Who we are as people certainly has an influence on the object of attraction, on the ultimate choice of sexual partner, or on the desire to engage in sex at all. There is no natural law that says this gender must have sex only with that other gender. Given this, can one really say definitively that these different classifications of sexuality (lesbian, homosexual or gay man, bisexual) are about sex, and not about gender? Would homosexuality still carry the stigma it does now, if it were considered in the context of a multigendered society? So how many genders are there? I say quite a few.

Native people of North America have noticed that, as they have attempted to revive many aspects of their cultures and return them to public life, it has not been enough simply to transpose what once was onto how and who they are today. For people and culture to survive, they need to evolve continually. What we as Indigenous people need to do is scrape off the stagnated scum from the culture in which we presently find ourselves immersed, pick up the residue of our historic cultures, and reblend the cultural pattern of who we really are today by following the roots inherent in the laws, values, and principles embodied in the old ways. This we need to do so that our grandchildren may find their way through to tomorrow with their humanity intact.

I note that the essence of what I have stated so far is in part documented in a number of publications by various contemporary anthropologists and ethnographers, though, I think, rather clumsily and incompletely. Some examples of flawed documentation relating to Native North Americans' perception of gender are Third Sex, Third Gender, edited by Gilbert Herdt (in particular the chapter "How to become a Berdache"), and the well-read The Spirit and The Flesh by Walter L. Williams. As in most social sciences, the documentation is the result of an observer's perceptions of the visual and oral materials received, filtered first through their European/Western 
sensibilities.This tends to give way to making pseudoequations and faulty extrapolations as they attempt to force the cultural information received to fit a preconceived European/Western framework.

As far as Herdt's and Williams's books are concerned, I first have to say that most of their observations are almost on track, and that these books do have some use-value. However, these texts are more telling for the limitations of the authors' perceptions, for how they interpreted what they looked at and what they were told. The faulty equations and extrapolations which they have made in trying to understand a phenomenon with which they had no connection have led, more often than not, to skewed conclusions. I have to say that probably the greatest disservice they have done is declaring us "Berdache," for this is the closest equation they can make from the world they know. This fundamental flaw - one that has colored their every view of us - established the sexual act as something primary. Their misunderstanding of our social organization and sense of spirituality lies at the root of the questionable extrapolations made from their observations. Everything else that rests on this faulty foundation must be suspect. Here I should like to quote Dr. NapeWasteWin Schutzer, a Blackfoot/Lakota psychologist based in England, who has an established European practice specializing in the treatment of transsexualism. She is also, like myself, a transformed woman, a Winkte in her language and culture. In the text of one of her videos, Winyanktehga, Two-Souls Person (which she uses in workshops as part of her practice), she says:

An old Lakota word, "Winyanktehga," has today been contracted to the simple word "Winkte," meaning "two-soulsperson." I am "Wakan." To my people I am sacred and mysterious, I am a spirit person. The Grandfathers tell me this. I have my feet rooted in the earth of my ancestors and my spirit soars with them in 'the land above the pines'. The anthropologists call me "Berdache," but this is wrong, this word has come a long way from its beginnings in Arabia. It means "kept boy" ... that I am not. The Western medical community calls me "transsexual," but this is not entirely true either. I am Winkte, a gender-crosser. My people see me as multidimensional and I do not have to fight for a place in my society to be accepted. I already have a place, a very special and sacred place. In my culture I represent a profound 
healing, a reconciliation of the most fundamental rift that divides human from human: gender ... My gender transformation was called for by the Spirits.

The major problem with the research and conclusions of the texts by Herdt and by Williams is that the focus of their study is men who take on the social role of women and who have had men as partners. Because of their inability to view these people as anything but men homosexual men - their research and was hugely compromised from the start. It led them to the presumption that the phenomenon they were observing was based more in sex or sexuality than in gender. Sex and gender are once again treated as synonymous. To their credit, they do at least make passing reference to this phenomenon in relation to women transformed to men. According to Paula Gunn Allen, in the Lakota language these women are referred to as Koshkalaka. ${ }^{5}$ Since Herdt and Williams make no mention of a transformed woman taking another woman as partner, or of a transformed man with another man, one is left with the impression that this type of pairing just did not happen. Of course, this is inaccurate. Though some peoples may have proscribed mating of this sort, it did happen, albeit less commonly. Simply because the authors were unable to locate such examples does not negate the existence of such individuals. Their analysis (one of a few with which I am in agreement) was that such situations occurred much less frequently, so there were fewer subjects to study, and when located they were less responsive. Herdt and Williams seem to have adopted the attitude that if it did not jump out at them, they were not going to pursue it. In choosing not to pursue this line, they again limited the comprehensiveness of their study of alternative gender. The one bright spot of this research is that it at least 'proves' (in European/North American eyes) the existence of various longstanding cultural practices that recognized genders existing beyond or outside of the male/female dichotomy of Western civilization. And they do provide photographic 'evidence' of the continuation of this phenomenon well into the twentieth century.

Two similarly problematic examples are a short essay by Will

${ }^{5}$ Winkte and Koshkalaka are Lakota words for their differently gendered people. Among the Cree they use the word Iskwew; with the Navajo it is Nadle. From my understanding and research, these words describe or name the same phenomenon. As well, the social positions accorded these special people among the various cultures were essentially the same. 
Roscoe titled "Living the Tradition: Gay American Indians" and Kenneth Steffenson's research paper Manitoba Native Peoples and Homosexuality. In most respects, they have less to do with my discourse than do the previous two writers. They perhaps best serve to illustrate some of the inherent problems with how data concerning Native gender and sexuality has been interpreted thus far. They are a bit more dangerous in that, looking at much the same information as above, they purport to portray the fundamental aspects of queerness among contemporary Native people. Yet, trans people are not considered; we are not part of their equation. These papers are both predetermined to focus solely on homosexuality, without really considering implications of gender beyond the male/female binary. The intent of Roscoe's essay is to document and make known the emergence of homosexual Natives in the United States and the establishment of the Gay American Indians 'movement,' and for this it is useful. However, at the time of writing, neither Roscoe nor gay American Indians considered trans people as being part of the equation.

In my view, these works contribute to the reinforcement of previous faulty scholarship on the subject and do nothing to further the discussion of gender. These works deal exclusively with predetermined male/female and gay/lesbian binaries, as if there were nothing else. Contrary to the stated aims of Steffenson's research, "to improve conditions," unfortunately, it serves rather to exclude and further marginalize those Natives beyond the labels of male, female, gay, and lesbian, as not being 'traditional.' Here again, I stress that just because these categories were all that the researchers/writers could perceive does not necessarily mean that this is all there is. Some of the Native people he classifies as homosexual are likely transgendered.

One last work I would like to acknowledge is Dr. Beatrice Medicine's pioneering paper “'Warrior Women' - Sex Role Alternatives for Plains Indian Women." Hers is the first 'authoritative' contemporary Native voice to speak on these issues. A preliminary version of Medicine's article was presented as a paper in 1973. While, as the title suggests, this work looks primarily at Plains Indian women, Medicine also refers to 'berdache', in a comparative commentary. I believe her point of view relates to my assertions. She argues that the whole idea that sex role reversals, for either women or 
men, constituted deviant forms of escapism from "normal" behavior is open to question. Instead of looking at sex role reversals as a form of "deviance" derived from "incompetence" in the roles associated with a person's gender, it might be more productive to examine them as normative statuses which permitted individuals to strive for self-actualization, excellence, and social recognition in areas outside their customary sex role assignments. In this light, changing sex role identity becomes an achieved act which individuals pursue as a means for the healthy expression of alternative behaviors. (268-69)

Medicine's scholarship, by not proceeding from a proscriptive focus on gender dichotomies, allows for the possibility that, though unseen, we trans people formed an important and diverse aspect of Plains Indian society. As she puts it, "the rich complexity of female gender roles and the variety of relations between women and men has been largely obscured" (276).

In the existing documentation, after the 1920s and 1930s in North America the issue of Native people who cross genders seems to evaporate. To explain this I must return to history. As colonization proceeded westward during the period from the late 1700 s to the late 1800 s, North America's Indigenous people were either exterminated, relocated, and/or "reserved" (the act of being forced onto often small areas of land called reservations). By and large, once reserved, we were ignored and left to our own devices, to survive or not. A semblance of Native peoples' cultural practices managed to continue, largely underground and hidden. Few practices remained in the public realm. In direct relationship to our proximity to expanding settler populations and to incursions by the church, the phenomenon of differently gendered people was driven underground. Throughout the course of the Depression, as destitute (white) men traversed the country in search of food and any kind of employment, many hundreds found themselves taken in by Native families on reserves, where they were fed and cared for. At that time, most Native people were still self-sufficient, with minimal connection to the settlers' monetary system. The great majority of Native people in North America did not experience the Depression as the rest of the populace did; we were largely unaffected. Chagrined and somewhat humiliated by this realization, I argue, the colonizer's push for assimilation went into 


\section{4 / Maracle}

high gear. Concerted efforts to pull Native people into the mainstream and to tie us to their economic system began in the late 1930s. Increasingly restrictive hunting and fishing laws were instituted; landuse policies on reserves became onerous to the point where many were forced to give up their agricultural pursuits; and the land lay dormant for maybe two generations. When welfare was extended to Native people - almost ten years after it was available to white folk virtually all initially refused to go along with the plan. Picking up on a trick from the missionaries (who would target either the 'chief' or the 'medicine man' for first conversion), as I see it, the government agents went after The Grandmothers in the communities, bringing them gifts, cajoling them, to convince them that welfare was a good idea. It took a few years, but it happened. As a result, we became an unproductive people, forcibly removed from the production of our own necessities of life. Now, after almost five decades of an unproductive dependence on welfare, a shift of large numbers of Native people to urban areas, and the conscious or unconscious adoption of Christian tenets, it is small wonder so many of us suffer from a lack of self-esteem and shaky cultural identity.

It is against this backdrop of a massive assault on our cultural ways of being in the twentieth-century, an assault even greater than that of the preceding centuries, that alternative genders disappeared or went underground. In Canada, speaking generally, in the east there has been maybe three generations of active homophobia in Native communities. Among the generation of my grandchildren, we have yet to see what is to come. In the west and north, where intensive colonization occurred later, homophobia can be traced back only within one or two generations. The silver lining here is the possibility of reversing this trend and repairing the damage, a change which is likely to happen in a far shorter time than ridding Western society of its genderphobia and homophobia in general, which have entrenched themselves over the last few hundred years.

From my point of view, little of any worth has been written by European or North American social scientists regarding Indigenous gender. I believe more Native writers need to grab the essence of who we were. We need to pick up the laws, values, and principles from the old stories, these things that have made us who we are and have supported and guided us through many millennia, and transform them into new stories, dance, and music that reflect this new people 
we have become. Then we might know where we are going and with whom we are moving forward. And so it is with myself and this gender for which I no longer have a name in my mother tongue. Being reasonably well-rooted culturally and historically, I am much more concerned with who we Winkte, we Iskwew, we Nadle, we Koshkalaka, we transformed people are in the here and now.

I am, and I am not, the same woman I would have been a few centuries ago. I am still a woman of some medicine. I create art. I have even been known to "prophesize with my pen" (thank you, Mr. Dylan). There have been Western surgical procedures available to augment my journey. Some may find this position a bit contradictory, perhaps citing that Native people historically had no comparable surgery available. I would assert that in the past, my powers of medicine and magics would have been much greater than what I possess today, and these would have allowed me to make a complete physical transformation. I offer myself as my own proof and defence: the initial development and growth of breasts, the rounding and softening of my body and face, and the change in my voice all came about from my knowledge and use of herbs in conjunction with my spirit. I dress to reflect my position just as I would have then, except that the materials and accessories have altered. And I still hold some influence as a gender warrior for today. A dear friend of many years, who is Iskwew, in seeing me dressed as a woman for the first time, had this to say: "You've always been [a warrior]; now, you're simply a warrior in a skirt." I have a vested interest in seeing how we special people are represented today by ourselves, to ourselves, and in mainstream society. Again I find myself in a place mediating between women and men and different cultures and worlds. Rather like in the past.

Throughout my journey in gender, and in writing this paper, I cannot help but be struck by the sameness between this discussion and what I have had to say and write about for some thirty years in relation to race. Indeed, from my experience, the genderphobic reactions I was subjected to in the early years of my transformation felt disturbingly similar to the racist shit directed at me as a Native man for so many years. Fear of change and conscious ignorance of difference are the breeding grounds of genderphobia, homophobia, sexism, racism, and xenophobia. Nowadays my life is relatively free from overt discrimination. This is relative to my previous life, relative 
to the subtle or blatant racism still directed at Native people, relative to the genderphobia and violence directed at transsexuals in North America. Perhaps the reduction in the discrimination I face is due to the fact that nowadays I can pass so well. But passing leaves me feeling ambivalent. Going out into the world over the last few years, I am seldom seen as Mohawk or even as Native. Rather, I tend to be viewed as an interesting-looking woman of indeterminate race, probably raised in the upper classes (I suspect this is because Native people are still largely regarded as being inarticulate, with poorly developed social skills). To pass as a woman is the great aspiration of almost all male-to-female trans people. However, for me, and for many others who came of age in the 1950s and 1960s, to pass racially has always implied betrayal and denial and thus represents a place I have never chosen to go. So nowadays I find it quite odd that I elicit more surprise from the revelation that I am Mohawk, than from the fact that I have not lived my whole life as the woman I have always been!

For the most part, Indigenous cultures have allowed for and encouraged difference. For us, it is simply one of the many natural elements necessary for the continued health, vibrancy, and wellbeing of (our) society. In my mind, queerness, oddity, is a desirable trait. It is by reconciling the differences in life that humanity moves forward. How societies choose to deal with difference attests to their level of humanity. It is not enough to tolerate patronizingly; we must learn acceptance of others' difference as a natural and necessary part of this wondrous pantheon known as humanity.

With this vision in mind, I contribute these thoughts on gender. If some of this may appear contradictory, perhaps it is. The natural world itself is full of contradictions. However, please make no mistake that my lack of academic credentials in any way lessens the validity of my position. I have spent half a lifetime pursuing these threads from our past, in order to make sense of the places I have had to travel in my personal journey to discover gender in its wholeness, and my place within it. 


\section{Works Cited}

Albers, Patricia, and Beatrice Medicine. The Hidden Half: Studies of Plains Indian Women. Baltimore: University of Maryland Press, 1983.

Allen, Paula Gunn. The Sacred Hoop: Recovering the Feminine in American Indian Traditions. Boston: Beacon, 1992.

Anzuldúa, Gloria, ed. Making Face, Making Soul/Haciendo Caras. San Francisco: Aunt Lute, 1990.

Erdoes, Richard, and John Lame Deer. Lame Deer: Seeker of Visions. New York: Simon, 1973.

Herdt, Gilbert, ed. Third Sex, Third Gender: Beyond Sexual Dimorphism in Culture and History. New York: Zone, 1994.

Maracle, Brian. Back on the Rez. Toronto: Penguin, 1996.

Moghadam, Valentine, ed. Identity Politics and Women: Cultural Reassertions and Feminisms in International Perspective. Boulder: Westview, 1994.

Nelson, E. D. and B. W. Robinson, eds. Gender in the 1990s: Images, Realities, and Issues. Scarborough: Nelson Canada, 1995.

Roscoe, Will. "Living the Tradition: Gay American Indians." Gay Spirit: Myth and Meaning. Ed. Mark Thompson. New York: St. Martin, 1988. 69-77.

Silvera, Makeda, ed. Piece of My Heart. Toronto: Sister Vision, 1991. Snitow, Ann, Christine Stansell, and SharonThompson, eds. Powers of Desire: The Politics of Sexuality. New York: Monthly Review, 1983.

Steffenson, Kenneth. Manitoba Native Peoples and Homosexuality: Historical and Contemporary Aspects. Winnipeg: Council on Homosexuality and Religion, 1987.

Vance, Carole S., ed. Pleasure and Danger: Exploring Female Sexuality. New York: Routledge, 1984.

Williams, Walter L. The Spirit and the Flesh: Sexual Diversity in American Indian Culture. Boston: Beacon, 1992.

Winyantecha: Two-Souls Person. Dir. Martin Marshall. Performed by NapeWasteWin. Leeds: NRG Films, 1998. 